\title{
LOS HIJOS DE MAYO: GENERACIONES Y POLÍTICA EN LA ARGENTINA, 1969-1994
}

\section{THE SONS OF MAY: GENERATIONS AND POLITICS IN ARGENTINA, 1969-1994}

\author{
VALERIA MANZANO (IDAES - UNSAM / CONICET) \\ Instituto de Altos Estudios Sociales \\ Universidad Nacional de San Martín \\ Consejo Nacional de Investigaciones Científicas y Técnicas \\ vmanzano@unsam.edu.ar
}

\begin{abstract}
Resumen:
Este artículo estudia cómo, cuándo y porqué diferentes grupos e individuos delinearon construcciones generacionales que tomaban al mayo de 1969 -y a otros mayos de comienzos de la década de 1970- como punto de referencia. Mostrará que las construcciones generacionales implican procesos de representación en un sentido doble. Por un lado, especialmente para el quinquenio que siguió a Mayo de 1969, el artículo reconstruye qué grupos y con qué significados políticos y culturales se auto-percibieron, por ejemplo, como "hijos del Cordobazo" e intentaron representar de esa manera tanto a un grupo de edad (joven) como a una posición y situación política. Por otro lado, representación aquí se vincula a las tareas de la memoria social, intentando también identificar de qué manera se desplazaron y transformaron las construcciones generacionales que cristalizaban, por ejemplo, en el marco de las conmemoraciones de fines de la década de 1980. En el último tercio de esa década, enmarcadas en procesos conmemorativos (especialmente, del vigésimo aniversario de las revueltas globales del '68) y en plena discusión sobre la valencia de conceptos y programas en torno a la "revolución", algunas memorias de militancia política emergieron imbricadas en clave generacional.
\end{abstract}

\section{Palabras clave:}

Generaciones - Juventud - Militancia Política - Memoria Social - Historia Reciente

\begin{abstract}
:
This article studies how, when, and why different groups and individuals delineated generational constructions that took May of 1969 -and other Mays in the early 1970s- as reference points. It will show that those generational constructions imply processes of representation in two senses. On the one hand, and especially for the five years that followed May of 1969, it reconstructs which groups (and with which political and cultural meanings) created a self-perception of being, for example, the "sons of the Cordobazo" and tried to represent an age group (youth) as well as a political position and situation. On the other hand, representation also refers to the tasks of social memory. In this respect, the article aims at identifying in which ways the generational constructions were transformed, for example, in the contexts of the commemorations of the late 1980s. In the last quarter of that decade, framed in commemorative processes (especially, the twentieth anniversary of the global revolts of 1968) and in the larger discussions over the legitimacy of concepts and programs related to the "revolutions", some memories of political militancy emerged in close association with generational positions..
\end{abstract}

\section{Keywords:}

Generations - Youth - Political Militancy - Social Memory - Recent History

Recibido: 11/11/2019 - Aceptado: 10/12/2019 


\section{LOS HIJOS DE MAYO: GENERACIONES Y POLÍTICA EN LA ARGENTINA, 1969-1994}

VALERIA MANZANO (IDAES - UNSAM / CONICET)

vmanzano@unsam.edu.ar

En 1994, al conmemorarse el 25 aniversario del Cordobazo, Carlos Altamirano delineó sus memorias sobre lo que define a la vez como "acontecimiento" y "mito". Desde ambos clivajes, Altamirano recurre a imágenes que dan cuenta del carácter disruptivo del Cordobazo, entendido como "llamarada" y "foco de irradiación energética" para un "nosotros" al que en ocasiones delimita como "quienes participaban de la izquierda maximalista" o, más generalmente, como quienes fueron "parte de la estela que siguió a aquel estallido". ${ }^{1}$ La muy difundida intervención de Altamirano introduce al menos tres elementos para intentar avanzar en una comprensión de construcciones generacionales. En primer lugar, la intervención -como buena parte de la producción académica, periodística y memorial, de antes y de ahora- sitúa al Cordobazo como la sinécdoque del conjunto de las rebeliones populares de 1969. En segundo lugar, ofrece pistas para interrogar la relación entre un "acontecimiento" y "mito" con la emergencia o transformación de un "nosotros": de un sujeto colectivo que se ligó política, cultural y afectivamente a esa experiencia. Entre otras dimensiones, ese "nosotros" constituye una construcción generacional. Por último, esa intervención se produjo en el marco de una conmemoración y se reconoce como una memoria. Así, esa intervención también ofrece indicios para historizar las construcciones generacionales en el marco de la historia de las memorias sociales sobre el pasado reciente. Mi objetivo es reconstruir la emergencia y los desplazamientos de construcciones generacionales ligadas a los "mayos", en un arco temporal que va desde 1970 hasta mediados de la década de 1990.

Esta historia de las construcciones generacionales enfatiza el trabajo de representación. En las ciencias sociales y humanas, el concepto de "generación" se ha vinculado con los postulados de Karl Mannheim, quien en su clásico ensayo de 1933 sostuvo que "los grupos de edad, como las clases sociales," dotan a los individuos de "una locación común en el proceso histórico y social, limitándolos a un rango específico de experiencias potenciales, predisponiéndolos a cierto modo característico de experiencia y pensamiento, y a un tipo característico de acción históricamente relevante". ${ }^{2}$ Un grupo de edad, para Mannheim, podría pasar de "en sí" a "para sí" en la medida en que, por ejemplo, determinadas experiencias lo aglutinaran (como las guerras o las revoluciones) y existiera un trabajo ideológico y político que le otorgase articulación. Las posibilidades heurísticas del concepto son tan amplias como sus límites. Entre estos últimos, los vectores que atraviesan a los miembros de un grupo de edad (de clase, región, género, sexualidad, religión, por mencionar unos pocos) van en detrimento de la chance de significar y experimentar de modo semejante acontecimientos que marcarían a todos y todas, una dificultad que han puesto en evidencia historiadoras e historiadores que abordaron estudios sobre juventud (el grupo de edad más

\footnotetext{
1 Altamirano, Carlos, "Memoria del 69", Estudios, núm. 4, diciembre de 1994, pp. 10-16.

2 Mannheim, Karl, "The Problem of Generations", en Essays on the Sociology of Knowledge, Londres, Routledge, 1952 (1933), pp. 276-319.
} 
asociado a los estudios generacionales). ${ }^{3}$ Antes que identificar, por ejemplo, a una "generación del Cordobazo", asumiendo así una perspectiva analítica generacional, en este artículo me interesa revisar cómo, cuándo y porqué diferentes grupos e individuos a lo largo del tiempo delinearon construcciones generacionales que tomaban al mayo de 1969 -y a otros mayos de comienzos de la década de 1970- como punto de referencia. El crítico cultural Leerom Medovoi ha sugerido que las "generaciones", como otros colectivos, se instituyen a partir del "acto hegemonizante de representación". ${ }^{4}$ En la historia que intentaré reconstruir, esa representación adquiere un sentido doble. Por un lado, especialmente para el quinquenio que siguió a Mayo de 1969, refiere a la posibilidad de reconstruir qué grupos y con qué significados políticos y culturales se autopercibieron, por ejemplo, como "hijos del Cordobazo" e intentaron representar de esa manera tanto a un grupo de edad (joven) como a una posición y situación política. Por otro lado, representación aquí se vincula a las tareas de la memoria social, intentando también identificar de qué manera se desplazaron y transformaron las construcciones generacionales que cristalizaban, por ejemplo, en el marco de las conmemoraciones de fines de la década de 1980. En este sentido, el artículo pretende colaborar con la historia de las memorias sociales de la militancia política. Mientras existe una abundante literatura que ha estudiado las cambiantes memorias de la dictadura y puesto el foco en la década de 1980, poco sabemos sobre cómo se procesaban las memorias sobre el pasado inmediato a la dictadura en ese mismo contexto. ${ }^{5}$ Así, busco mostrar que, en el último tercio de esa década, enmarcadas en procesos conmemorativos (especialmente, del vigésimo aniversario de las revueltas globales del '68) y en plena discusión sobre la valencia de conceptos y programas en torno a la "revolución", algunas memorias de militancia emergieron imbricadas en clave generacional.

Este ensayo se organiza en tres apartados que siguen un orden a la vez cronológico y temático. Primero, el foco estará puesto en el quinquenio que siguió a Mayo de 1969, concentrándome en las producciones de diversos grupos dentro del movimiento estudiantil universitario tanto como en las de agrupaciones de izquierda y peronistas. Mientras que entre las agrupaciones de izquierda (estudiantiles o no) rápidamente emergió una auto-percepción de haber sido "hijos del Cordobazo", para quienes se enrolaban dentro de las variantes peronistas la filiación no era tan intensa. Para estas últimas, especialmente las que se ligaban a Montoneros, con el correr de la década de 1970 "Mayo" solapaba diversos significados ligados a acontecimientos caros a esa familia política: el secuestro del ex presidente Pedro Eugenio Aramburu (en 1970), el inicio del gobierno de Héctor Cámpora (en 1973) o la confrontación con Juan Perón el 1 de mayo de 1974. Si bien para la familia del peronismo que se autoproclamaba por la revolución el Mayo de 1969 en general, y el Cordobazo en particular, se diluían como punto de referencia, no sucedía lo mismo para activistas y militantes de esa tendencia afincados en Córdoba, un elemento que permite ponderar lo significativo de las escalas geográficas, en este caso la provincial e incluso local, para comprender las construcciones generacionales. Esas escalas fueron particularmente significativas para analizar un segundo momento. En la década de 1980, esas construcciones que tomaban a los "mayos" como marco de referencia se imbricaron con los modos en que diversos actores políticos y culturales rememoraron el ciclo de revueltas globales de 1968. Fue esa la ocasión en la cual comenzaron a visibilizarse construcciones generacionales producidas desde las memorias de la militancia y, más generalmente, de la revolución, asociadas a un pasado en el cual los "mayos" volvían a visitarse y evocarse. A pesar de los desplazamientos, ciertos nudos continuaron

\footnotetext{
${ }^{3}$ Jobs, Richard, Riding the New W ave: Postwar Youth and the Rejuvenation of France, Standord, Stanfdord University Press, 2007, pp. 10-17; Neumann, Mathias, "Youth, it is your Turn!: Generations and the Fate of the Russian Revolution (1917-1932), Journal of Social History, vol. 46, núm.. 2, 2012, pp. 273-304.

${ }^{4}$ Medovoi, Leerom, Rebel: Youth and the Cold War Origins of Identity, Durham, Duke University Press, 2005, 216.

5 Sobre las memorias de la dictadura en la década de 1980, ver especialmente Vezzetti, Hugo, Pasado y presente; guerra, dictadura y sociedad en la Argentina, Buenos Aires, Siglo XXI, 2002; Crenzel, Emilio, La historia política del Nunca Más, Buenos Aires, Siglo XXI, 2008; y una revisión panorámica en Lvovich, Daniel y Jaquelina Bisquert, La cambiante memoria de la dictadura, Buenos Aires, Universidad Nacional de General Sarmiento, 2008.
} 
desplegándose, notablemente la centralidad que tuvo el "mayo de 1969" para referentes de izquierda y su oclusión entre quienes continuaban filiados, aun simbólicamente, con el peronismo. Para unos y otros, sin embargo, los procesos de recuerdo se organizaban en clave generacional. En las conclusiones, el artículo recupera -de forma exploratoria- las transformaciones en los procesos memoriales en la primera mitad de la década de 1990, dando cuenta de la pregnancia que fue ganando la clave generacional para encapsular las militancias políticas y que se torna evidente, por ejemplo, en la emergencia de una "generación del setenta".

\section{Entre Mayos}

Quienes estudiaron al movimiento obrero han sostenido, con razón, que el Cordobazo representó la cristalización -antes que el inicio- de tradiciones de lucha, demandas y alianzas que venían configurándose al menos desde fines de la década de $1950 .{ }^{6}$ En igual sentido, los historiadores del movimiento estudiantil en diferentes universidades nacionales han remarcado también que las transformaciones ideológicas, organizativas y culturales de este actor colectivo de gran visibilidad en 1969 se remontaban, como mínimo, a mediados de la década de 1960, cuando se delineaban contornos de una dinámica de radicalización política que fue impregnando a segmentos cada vez más amplios del estudiantado. ${ }^{7}$ Movimiento obrero y estudiantil fueron, a lo largo de la década de 1960, dos de los espacios clave para los debates sobre y, más importante, la emergencia de una "nueva izquierda" en la cual predominaron las resignificaciones del fenómeno peronista y las disputas sobre las posibles "vías" para una revolución que, para muchos, ya estaba en marcha -no sólo en la Argentina sino también en el resto de América Latina. ${ }^{8}$ Contemporáneamente, sin embargo, las revueltas de 1969 tuvieron un efecto sorpresa, incluso para los grupos estudiantiles, intelectuales y obreros más activados. Retomando las memorias de Altamirano, ese ciclo de protestas, y en especial el Cordobazo, por un lado "daba forma a expectativas que lo precedían" pero, por el otro, "permaneció flotante al menos hasta 1972-1973". Esa doble vertiente marca las coordenadas de la relevancia del "acontecimiento" y "mito", especialmente en su capacidad de instituirse como marco de referencia para construcciones generacionales que, ancladas en diversas tradiciones de la izquierda, se auto-representarían como "hijas del Cordobazo". En la acelerada dinámica de politización y radicalización de amplios segmentos de la sociedad argentina que se desplegó en el quinquenio siguiente a Mayo de 1969, otras familias políticas -en particular, el peronismo que se proclamaba revolucionario- ubicaron al "acontecimiento" y "mito" en una zaga más larga, diluyendo su potencia simbólica para la producción de construcciones generacionales. Esa dilución, sin embargo, no alcanzó a quienes fueron activistas y militantes (por lo general, jóvenes) en Córdoba, algo que ilumina los significados de las escalas geográficas para la elaboración de construcciones generacionales.

En las memorias de Carlos Altamirano, y en las de otros y otras que experimentaron en términos personales las dinámicas de radicalización política de fines de la década de 1960 y comienzos de la siguiente, suelen remarcarse las "expectativas" que precedieron al Mayo de 1969. Aunque desarrollaré este punto en el próximo apartado, en las memorias esas "expectativas" se ligaban al

\footnotetext{
${ }^{6}$ Brennan, James, The Labor Wars in Córdoba, 1955-1976: Ideology, Work, and Labor Politics in an Argentine Industrial City, Cambridge, Mass, Harvard University Press, 1994; Gordillo, Mónica, Córdoba en los sesenta: la experiencia del sindicalismo combativo, Córdoba, Universidad Nacional de Córdoba, 1996.

7 Millán, Mariano, "Entre la Universidad y la política: los movimientos estudiantiles de Corrientes y Resistencia, Rosario, Córdoba y Tucumán durante la Revolución Argentina (1966-1973)", Tesis doctoral, Facultad de Ciencias Sociales, Universidad de Buenos Aires, 2013; Califa, Juan Sebastián, Reforma y revolución: la radicalización politica del movimiento estudiantil de la UBA, 1943-1966, Buenos Aires, EUdeBA, 2014; Vega, Natalia, "De la militancia estudiantil a la lucha armada: Radicalización del estudiantado universitario santafecino en la segunda mitad de la década de 1960", Tesis doctoral, Universidad Nacional de Entre Ríos, 2016.

${ }^{8}$ Tortti, María Cristina, El "viejo" Partido Socialista y los orígenes de la "nueva izquierda" (1955-1965), Buenos Aires, Prometeo, 2009; Aldo Marchesi, Latin America's Radical Left: Rebellion and Cold War in the Global Sixties, Nueva York, Cambridge University Press, 2017.
} 
modo en que se recibían y procesaban las noticias de las revueltas globales que hicieron al "momento 68". Como lo he estudiado en otros trabajos, la prensa gráfica argentina siguió de cerca aquellas revueltas y, más allá de las divergencias en coberturas y opiniones, resaltaban dos singularidades. Por un lado, en virtud de relaciones e intereses político-culturales de largo plazo, las revueltas parisinas recibieron una cuota preponderante de la cobertura en revistas y periódicos de interés general y también políticas. Esa preponderancia obliteró la cobertura de otras locaciones de revuelta, como las diversas ciudades italianas o, más adelante en 1968, México o Montevideo. Por otro lado, con el acento puesto en París, la cobertura también enfatizaba en los aspectos que se consideraban novedosos de las revueltas, como el tono iconoclasta de los grafiti, la gravitación de segmentos de intelectuales que -se recortaba- proponían rever el "rol" del proletariado en procesos revolucionarios (Herbert Marcuse era el más mencionado), y en la omnipresencia de rostros jóvenes, estudiantiles, en las calles. 'Teniendo en cuenta que esos eran los materiales disponibles, no es de extrañar que quienes fueran convocados a opinar sobre esas revueltas y sobre qué sucedía, o sucedería, en la Argentina, lo hicieran munidos de esas imágenes y esos énfasis, antes que con otros elementos de análisis.

Las revueltas del "momento 68" delimitaban las "expectativas" aunque en líneas generales éstas se delinearan por oposición, antes que por acercamiento, con lo que se interpretaba estaba sucediendo a escala europea y especialmente parisina. Mientras que la Federación Universitaria Argentina ([FUA] conducida por militantes que recientemente habían roto con el Partido Comunista y comenzaban a acercarse al maoísmo) lanzó un manifiesto en solidaridad con los estudiantes y, en especial, los trabajadores franceses en mayo de 1968, muchos otros estudiantes cuestionaban la validez de las demandas y los actores que veían como preponderantes en las revueltas europeas. ${ }^{10}$ Así, por ejemplo, quien era portavoz de una organización que nucleaba a estudiantes de origen católico en rápido tránsito hacia el peronismo, la Unión Nacional de Estudiantes (UNE), al ser consultado por movilizaciones en la Argentina, sostenía que "para la muchachada que hoy sale a la calle, sus padres históricos son el federalismo, el yrigoyenismo y el peronismo: nos importan un bledo Marcuse y Marx". Roberto Grabois, su colega del Frente Estudiantil Nacional (FEN), sostenía por su parte que "los estudiantes apoyarán la Revolución de los Trabajadores. Quienes piensan que los trabajadores deben apoyar la revolución de los estudiantes, seguirán soñando en París mientras la historia se gesta en Avellaneda, en Tucumán y en cada barrio y provincia de la patria". "Aun para quienes, con el transcurrir de los meses, produjeran interpretaciones más matizadas sobre las demandas y los actores de las revueltas europeas -como Sergio Caletti, quien enfatizaba que "los dirigentes estudiantiles franceses siempre declararon que las masas trabajadoras podían y debían ponerse al frente"- las comparaciones seguían al orden del día: "No es la expresión anárquica, inorgánica, de los objetivos revolucionarios los que pueden llevar a la victoria en las tierras americanas. "Nuestras" luchas no podían ser como las europeas (o como esos estudiantes e intelectuales las representaban): "aquî" los estudiantes debían seguir a los trabajadores.

Las interpretaciones que se construyeron en el ámbito estudiantil e intelectual respecto a las revueltas globales, singularizadas en el mayo parisino de 1968, contribuyeron a configurar las expectativas respecto a lo que potencialmente podría -y, al criterio de muchos activistas y militantes, debería- suceder en la Argentina. ${ }^{13}$ En los inicios del mayo argentino de 1969, los movimientos

\footnotetext{
${ }^{9}$ Manzano, Valeria, La era de la juventud en la Argentina: cultura, politica y sexualidad desde Perón hasta Videla, Buenos Aires, Fondo de Cultura Económica, 2017, cap. 6; “A cincuenta años de las revueltas de 1968”, Ciencia Hoy, núm. 160, julio de 2018.

10 "Solidaridad con los trabajadores y los estudiantes de Francia", Vocero de la FUA, núm. 2, mayo-junio de 1968 , p. 5. 11 "Hablan los dirigentes estudiantiles", Semanario CGT núm. 33, diciembre de 1968.

${ }^{12}$ Caletti Sergio, "Mayo, Francia, barricadas", Cristianismo y Revolución, núm. 16, segunda quincena de mayo de 1969, pp. 18-19.

${ }^{13}$ En el ámbito estudiantil y profesional, una experiencia que sí recogió diversas ideas, imaginarios y prácticas asociadas al ciclo de revueltas del 68' europeo fue la de la Facultad de Arquitectura de la Universidad Nacional de Córdoba, ver Malecki, Juan Sebastián, “¿Una arquitectura imposible? Arquitectura y política en el Taller Total de Córdoba, 1970-
} 
estudiantiles de las universidades del Nordeste y Rosario estuvieron en el centro de la escena: fueron, de hecho, la vanguardia del ciclo de revueltas y el blanco de la creciente represión estatal que resultó en el asesinato de tres jóvenes y el encarcelamiento de otros cientos en una semana, la que fue desde el 15 al 22 de mayo. Desde la prensa comercial hasta la más politizada no dudaron en calificar a esa semana como la de "la rebelión de los estudiantes" o "la rebelión estudiantil", reconociendo que el activismo estudiantil había servido para hacer visible, en la práctica y en las calles, alianzas políticas y sociales de mediano plazo, que incluían a sectores del movimiento obrero (en especial, bajo el paraguas de la Confederación General del Trabajo de los Argentinos, o CGTA) y segmentos de las clases medias y populares que acompañaron a los estudiantes en sus reclamos iniciales e hicieron públicas, con ellos, su oposición al gobierno de Juan Carlos Onganía. ${ }^{14}$ Sin embargo, en la evaluación inmediatamente posterior al masivo levantamiento rosarino, donde "el pueblo" se había sumado a una protesta iniciada por los estudiantes, casi todos los dirigentes universitarios lo juzgaron insuficiente: el movimiento estudiantil aún no había adquirido "el carácter de lucha popular" capaz de conducir a la "liberación nacional". Según el representante maoísta de un frente de izquierda, "la condición para que se generalicen [las luchas de los estudiantes] es la dirección obrera hegemónica. Hasta entonces los brotes serán aislados y corren el peligro de ser aprovechados por la oposición que no ataca las raíces del sistema". Con las correspondientes variaciones, el vocero de los grupos que tomaban "al peronismo como punto de partida para el proceso revolucionario" hizo una evaluación similar: "Los dirigentes estudiantiles aportaremos al proceso iniciado, sin pretensiones de conducción, porque tenemos confianza en la conducción de la clase trabajadora". ${ }^{15}$ En sintonía con el lema que guiaba a la militancia estudiantil, los dirigentes universitarios minimizaban las protestas lideradas por los estudiantes. Tanto para ellos como para casi todos los observadores de entonces y de hoy, el punto de inflexión sería, por supuesto, el Cordobazo. En la medida en que la participación del movimiento obrero en Córdoba fue mucho más decisiva y numerosa, y que los trabajadores mostraron un nivel de combatividad callejera que sorprendió a propios y ajenos, el Cordobazo vino a colmar las expectativas de diversos sectores activados, incluyendo a las dirigencias estudiantiles de diversas tradiciones políticas. Episodio final del ciclo de revueltas del mayo argentino, el Cordobazo devino prontamente su sinécdoque. Y si bien, como planteaba Altamirano en sus memorias del '69, su significado "permaneció flotante por un tiempo", diferentes grupos y partidos intentaron prontamente anclarlo. En esos procesos de anclaje interpretativo se modelaron, también, construcciones generacionales.

En el marco del movimiento estudiantil, una de las primeras ocasiones para el anclaje de significados y, con ellos, las construcciones generacionales que tomaban como referencia al mayo de 1969 fue la convocatoria al IX Congreso de la FUA. Los convocantes, pertenecientes al comunismo en proceso de acercamiento al maoísmo, remarcaban en el llamado: "nunca como ahora obreros y estudiantes, hemos combatido contra los agentes de la represión, fundiendo nuestro futuro en la hoguera de la rebelión popular que se extendió desde el paupérrimo Nordeste hasta la Córdoba industrial y obrera". Ante esa constatación, se hacía más imperioso la construcción de la "unidad del movimiento estudiantil" -que, esa dirigencia entendía, solo podía darse en el marco de la FUA- para que participara de un bloque "antidictatorial, por la liberación nacional y social”. Como lo venía haciendo desde el bienio anterior, la dirigencia de la FUA reconocía que el estudiantado se estaba organizando también por fuera de esa federación, y por eso mismo

\footnotetext{
1975”, Prismas, núm. 22, 2018, pp. 95-115. Para las reverberaciones del 68' europeo y norteamericano en segmentos contraculturales, ver Manzano, La era de la juventud..., op. cit., cap. 5.

${ }^{14}$ La tapa del semanario Panorama del 22 de junio de 1969 sobreimprimía la leyenda "La rebelión de los estudiantes" a una foto de una manifestación en Rosario. Asimismo, el periódico Cristianismo y Revolución, en su número 17 (primera quincena de junio de 1969), sintetizaba en su tapa y en su nota editorial que se había tratado de una "Rebelión estudiantil", mientras que en su contratapa publicaba una foto de Juan José Cabral, el primer estudiante asesinado en Corrientes, con la leyenda "dio su vida por una nueva juventud".

15 "Dirigentes universitarios, después del desborde”, en Panorama, núm. 109, 27 de mayo de 1969, pp. 8-11. Ver también "Estudiantes, los fantasmas tienen nombre”, Panorama, núm. 110, 3 de junio de 1969, p. 14.
} 
convocaba especialmente a los "nacionales" a sumarse al Congreso. ${ }^{16}$ Mientras que fuerzas de la izquierda (incluyendo grupos ligados al Partido Revolucionario de los Trabajadores [PRT]), aunque con críticas, asistieron a la cita, los "nacionales" la desconocieron. El Frente de Estudiantes Nacionales, por ejemplo, insistió con que la FUA había hecho solamente una crítica "maquillada" al rol de la federación durante la década peronista y, más fundamentalmente, sostenía que las formas organizativas (centros, federaciones) se correspondían con un tipo de "parlamentarismo liberal" que no tenía sentido en la Argentina, "mucho menos desde el Cordobazo". ${ }^{17}$ Realizado, como podía esperarse, en la ciudad de Córdoba, el IX Congreso de la FUA eligió como presidente a Jacobo Tieffemberg, un médico pediatra y estudiante de psicología en la Universidad de Buenos Aires, miembro del Frente de Agrupaciones Universitarias de Izquierda (FAUDI). Al ser consultado sobre de qué manera podría revitalizarse la federación, Tieffemberg enfatizaba que el único programa "realista" para el movimiento estudiantil y para la universidad se entroncaba con el proceso de "liberación popular" y el método era el de la "insurrección popular, como nos enseñara el Cordobazo, del que somos hijos". ${ }^{18}$

La interpretación inmediata del Cordobazo como momento bisagra de la política argentina se imbricaba, en algunas inflexiones, con su representación como acontecimiento fundante de una nueva "etapa"-de movilización popular- y de un colectivo de "hijos", o una generación marcada por ese acontecimiento. Así, cuando en 1970 salieron a la superficie organizaciones guerrilleras de alcance nacional, éstas intentaron justificar su legitimidad en las tres circunstancias que, a su criterio, el Mayo argentino había puesto en evidencia: la determinación popular de luchar contra el régimen, los límites de la "insurrección" frente a la represalia de los militares y la violencia "desde arriba" que ellos aspiraban a contraatacar "desde abajo". "19 Sin embargo, fueron especialmente las organizaciones de izquierda, armadas o no, las que con mayor énfasis dotaron al Cordobazo de un carácter fundante -en su doble valencia, de una "etapa" y de unos "hijos". Tal fue el caso, por ejemplo, de dos de los partidos maoístas, Vanguardia Comunista y el Partido Comunista Revolucionario -al cual pertenecía Jacobo Tieffenberg- ambos identificando de modo inmediato el carácter de parte-aguas que había tenido el Cordobazo para las luchas populares y, el primero, yendo un paso más allá al trasladar a todo su comité de dirección a la provincia de Córdoba. ${ }^{20} \mathrm{En}$ igual sentido, el PRT también consideró rápidamente que el Cordobazo representaba "un hito histórico para el proletariado argentino", marcando sustantivamente el inicio de una nueva "etapa". Más singularmente, el Cordobazo también había "parido" a una nueva camada de militantes. En los múltiples obituarios para militantes caídos o asesinados, especialmente si habían sido estudiantes o provenientes de los sectores medios, quienes redactaban la prensa del PRT enfatizaban la centralidad que había tenido el Cordobazo en su formación y transformación. Así, por ejemplo, un obituario para Juan del Valle Taborda, quien había sido estudiante de agronomía, asociaba las jornadas de Mayo como un rito de pasaje: "su militancia se activó en el Cordobazo". El obituario para Ramiro Leguizamón era aún más enfático: "Pertenecía a esa camada de valientes estudiantes que a partir del Cordobazo comprendieron la necesidad de unir sus vidas a la causa del pueblo, que supieron abandonar las comodidades y privilegios que podrían brindarles sus orígenes de clase, sus carreras, y entregarle todo a la revolución". ${ }^{22}$ El PRT producía una representación del

\footnotetext{
16 "Llamamiento de la FUA al IX Congreso", Cristianismo y Revolución, núm. 22, enero de 1970, pp. 21-26.

17 "Declaraciones del FEN", Cristianismo y Revolución, núm. 22, enero de 1970, pp. 32-34; "La UNE ante la crisis reformista”, Cristianismo y Revolución, núm. 27, enero de 1971, p. 40.

18 "Nuevo presidente de la FUA: No somos los de antes", Panorama, núm. 140, 30 de diciembre de 1969, p.9.

19 Véanse, por ejemplo, "Hablan los Montoneros", Cristianismo y Revolución, núm. 26, noviembre-diciembre de 1970 , pp. 10-14; “A dos años del Cordobazo”, Estrella Roja, núm. 3, junio de 1971, p. 3.

${ }^{20}$ Ver Rupar. Brenda, "Emergencia y consolidación de la corriente maoísta en la Argentina: antecedentes, fundamentos y caracterización (1965-1974)", Tesis doctoral, Departamento de Historia, Facultad de Filosofía y Letras, Universidad de Buenos Aires, 2019, cap. 5.

${ }^{21}$ Carnovale Vera, Los combatientes: Historia del PRT-ERP, Buenos Aires, Siglo XXI, 2011.

22 “Juan del Valle Taborda”, Estrella Roja, núm. 2, mayo de 1971; "Ramiro Leguizamón”, Estrella Roja núm. 30, febrero de 1974, y pueden consultarse también "Ivar Barolo" y "José Luis Buscarioli”, Estrella Roja, núm. 39, agosto de 1974.
} 
Cordobazo que implicaba, también, una construcción generacional: el Cordobazo no solamente habría abierto una nueva etapa de la lucha de clases sino que, al hacerlo, se instituía como experiencia constitutiva de una nueva generación. El supuesto referente empírico de esos "hijos del Cordobazo" no era aleatorio: se trataba de jóvenes universitarios, cuyos orígenes sociales se situaban entre las clases medias y acomodadas, que habrían atravesado al Cordobazo como un rito de pasaje hacia el encuentro con sus "otros" sociales y culturales. La productividad del Cordobazo era doble: desde esa perspectiva, expresó y sentó las condiciones para una nueva "etapa" a la vez que delimitó los contornos de una generación que haría posible, idealmente, llevar adelante sus potencialidades.

Desde otras esquinas de las organizaciones que se proclamaban revolucionarias, en especial las peronistas filiadas con Montoneros, mayo de 1969 no tuvo la misma productividad. Muchos de los grupos "nacionales" en medios universitarios -como mencioné más arriba- tanto como la propia organización Montoneros reconocieron rápidamente que el Cordobazo había representado un viraje significativo en la política argentina, ya sea porque habría mostrado la creciente combatividad y politización de los trabajadores como porque habría significado la "incorporación de los estudiantes [de las clases medias] a la lucha contra el régimen, contra el cual la clase obrera lucha hace un cuarto de siglo", al decir de un sociólogo que evocaba, con el último señalamiento, a 1945 y el "nacimiento" del peronismo. ${ }^{23}$ En una tradición política que reconocía otros "hitos" -1945 , 1955 y el inicio de la "resistencia", entre otras- mayo de 1969 podía insertarse con mayor o menor pregnancia, pero su relevancia para la construcción generacional se difuminaba vis-a-vis lo que sucedía de modo contemporáneo con las fuerzas de izquierda. ${ }^{24}$ Mucho más, para quienes en la primera mitad de los años 1970 se filiaron con los Montoneros, la misma fecha, el 29 de mayo, remitiría a otro suceso: el secuestro del ex presidente Pedro Eugenio Aramburu y, con él, el bautismo público de aquella organización. De hecho, ese suceso tuvo lugar precisamente cuando se conmemoraba el primer aniversario del Cordobazo, una fecha emblemática precedida por una quincena de intenso activismo, especialmente en los medios estudiantiles, protagonizado por grupos de diversas tradiciones, que incluían a comunistas, radicales, fracciones del socialismo, y también del peronismo universitario. La segunda quincena de mayo de 1970 estuvo jalonada por movilizaciones estudiantiles en Corrientes, Resistencia, Tucumán, Buenos Aires, La Plata, Rosario y, por supuesto, Córdoba. El 21 de mayo, en esta última ciudad la represión policial fue particularmente intensa, resultando en decenas de heridos de gravedad y 1500 detenidos y detenidas -como se encargaba de mostrar la prensa periódica a partir de las fotografías que ocupaban sus portadas. ${ }^{25}$ Sin embargo, las portadas de los diarios del 30 de mayo ya estaban divididas entre dos noticias: las crónicas por la conmemoración del Cordobazo (que en Córdoba resultaron en otros 180 detenidos) y los primeros titulares que indicaban que "habría sido secuestrado Aramburu". ${ }^{26}$ En una de las primeras reconstrucciones posteriores, el periódico Montonero La causa peronista indicaba que la elección de la fecha obedecía tanto a la conmemoración del aniversario del "levantamiento obrero" como a las efemérides del Día del Ejército. ${ }^{27}$ Sin embargo, en los comunicados de Montoneros no había referencia alguna al "levantamiento obrero", cuyo primer aniversario quedó opacado por la resonancia del secuestro de Aramburu y su ejecución a los dos días.

\footnotetext{
${ }^{23}$ Cárdenas, Gonzalo, "El movimiento nacional y la universidad”, Antropología Tercer Mundo, núm. 3, noviembre de 1969.

${ }^{24}$ Ver especialmente Slipak, Daniela, Las revistas montoneras: cómo la organización construyó su identidad a través de sus publicaciones, Buenos Aires, Siglo XXI, 2015, pp. 74-100.

25 “Agitación estudiantil”, La Razón, 21 de mayo de 1970, p. 9; “Graves sucesos en Córdoba”, La Razón, 22 de mayo de 1970, pp. 1, 5-6.

${ }^{26}$ Ver, por ejemplo, “Agitación estudiantil” y “Aramburu habría sido secuestrado”, La Razón, 30 de mayo de 1970, p.1;

"A un año de los sucesos de Córdoba" y "Noticias sobre Aramburu", Clarín, 30 de mayo, p.1.

27 “Cómo murió Aramburu”, La causa peronista, núm. 9, 3 de septiembre de 1974.
} 
De manera sucinta, la irrupción pública de Montoneros yuxtapuso un nuevo "mayo", que en los años siguientes sería integrado a una zaga más amplia que construían aquellos que participaban de esa variante que se proclamaba por la revolución, y que serviría para crear construcciones generacionales propias. Así, por ejemplo, en ocasión de la celebración por la victoria de Héctor Cámpora en mayo de 1973, el periódico Montonero El descamisado produjo un informe -con abundancia de fotografías- recapitulando las luchas populares desde 1955 hasta 1973. En el informe, el Cordobazo ameritaba una sola fotografía, con el epígrafe "el pueblo entró a tallar". ${ }^{28}$ Un año más tarde, al conmemorarse el quinto aniversario del mayo de 1969, en otra publicación de esa tendencia un "montonero" contaba en primera persona sus experiencias, enfatizando la emergencia de grupos universitarios peronistas tras el golpe de Onganía y su gravitación, indicaba, en las jornadas de Córdoba, algo que a su criterio permitía "cuestionar la interpretación de la zurda, que se adjudica su paternidad". Esa "zurda" habría estado errada ya que, aseguraba el "montonero", el Cordobazo no marcó el "inicio de ninguna revolución". ${ }^{29}$ Ya en 1975, desde otro periódico Montonero, se buscaba clarificar una vez esa mirada sobre mayo de 1969: "nacido en el pueblo peronista", sostenía, "el Cordobazo no encontró al movimiento de liberación nacional a su altura". Ese movimiento habría encontrado "su altura" recién al mayo siguiente, esto es, en 1970, cuando Montoneros secuestró y ejecutó a Aramburu, y mucho más en el mayo de 1973, con la llegada de Cámpora al gobierno. El mayo siguiente, el de 1974 -marcado por la confrontación pública entre Montoneros y Perón- sintetizaba, para esa interpretación, un momento de mayor autonomía aún para el "movimiento de liberación nacional". ${ }^{30}$ Estas interpretaciones, seguramente compartidas por segmentos importantes de quienes se enrolaban en el peronismo en su variante Montonera, ponían el acento en una pluralidad de "mayos" aunque eran los de 1970 y 1973 los que se instituían como marco de referencia para construcciones generacionales que -como mostraré en el apartado siguiente- emergieron desde dinámicas memoriales, esto es, a partir de procesos de representación del pasado.

Sin embargo, de modo contemporáneo, los significados del mayo de 1969 fueron diferentes si se los entendía a escalas provinciales o locales. Tal fue el caso, por ejemplo, de aquellos militantes y activistas de Córdoba. Aunque mucha más investigación será necesaria en este punto, una revisión de la prensa montonera radicada en esa provincia coloca al Cordobazo en un lugar mucho más central de la zaga de "luchas populares": se trataba del "glorioso 29 de mayo, cuando la clase trabajadora de Córdoba derrumbó en las calles los sueños imperiales de Onganía, y nuestra ciudad fue convirtiéndose en una de las presas más buscadas de las clases dominantes". ${ }^{11}$ La (auto) representación del activismo cordobés como pionero de las luchas populares situaba en el centro a los trabajadores y a los jóvenes, estos últimos entendidos como "herederos de mayo del 69, en la senda de La Calera", en referencia a los montoneros que tomaron esa localidad cordobesa de 1 de julio de $1970 .{ }^{32}$ Como lo ha mostrado Mónica Gordillo, para los trabajadores cordobeses la construcción del Cordobazo como un símbolo "llegó a eclipsar a otras fechas simbólicas, como el 1 de mayo o el 17 de octubre". El Cordobazo, en tanto símbolo, se instituyó como un eje significativo de disputas políticas entre los peronismos de diversas variantes -no solamente el alineado con Montoneros- y también entre éstos y los grupos de izquierda. En 1973, las disputas parecieron suspendidas: tras un homenaje oficial por parte del Consejo Deliberante, las conmemoraciones centrales contaron con la presencia del presidente cubano Osvaldo Dorticós, quien visitaba Córdoba tras haber participado en el acto de asunción de Cámpora. "Cuba va del brazo, de nuestro Cordobazo" fue el cantito entonado por militantes y activistas, obreros y

\footnotetext{
28 "18 años de lucha", El descamisado, núm. 2, 29 de mayo de 1973.

29 "Un montonero cuenta el Cordobazo", El peronista lucha por la liberación, núm. 6, mayo de 1974.

30 "Cuatro mayos", Evita Montonera, núm. 4, abril de 1975, pp. 32-33.

31 "Fracasó el zarpazo gorila en Córdoba", El peronista, núm. 3, 24 de julio de 1973.

32 “¡Hasta la victoria siempre!”, El peronista, núm. 11, tercera semana de noviembre de 1973.
} 
estudiantes, tanto de la izquierda como de los diversos peronismos. ${ }^{33}$ Pero esa "primavera" fue breve, y ya para el quinto aniversario de Mayo de 1969 poco quedaba, en Córdoba y en el resto del país, de las posibilidades de pensar en que la Argentina seguiría "del brazo de Cuba".

Antes que "flotante por un tiempo", como lo planteara Altamirano desde sus memorias, los significados del Cordobazo -y de las revueltas de Mayo de 1969- estuvieron, durante el quinquenio que les siguió, en el centro de las disputas políticas y culturales de nuevos y viejos grupos que se auto-proclamaban revolucionarios. Grupos de izquierda, notablemente el PRT, rápidamente lo identificó como una cesura que marcaba el inicio de una "nueva etapa" y también el "rito de pasaje" mediante el cual jóvenes que provenían de orígenes no proletarios terminaban de fundirse con la causa revolucionaria. Contemporáneamente, algunos intelectuales y dirigentes peronistas interpretaban a las revueltas de Mayo del " 69 en un sentido similar, o sea, como la instancia en que "el estudiantado" -que se asumía de clase media- se había fundido con el pueblo, una fusión que desde esta vertiente tendría otros "mayos" (el de 1970, o de 1973) a ser reconocidos y reivindicados como enteramente propios. En el quinquenio que siguió a Mayo del '69, entonces, se fueron sucediendo varios otros "mayos" con la potencialidad de constituirse en "acontecimiento" y "mito", y así como marco de referencia para construcciones generacionales. Llamativamente, en un espacio que hacía uso de una posición de edad (juventud) como índice de diferenciaciones político-ideológicas, las dinámicas de construcción generacional fueron más débiles que entre las agrupaciones de izquierda. Aunque quede mucho por explorar, esa debilidad de los grupos asociados a Montoneros para (auto) representar una generación quizá obedezca a la voluntad de integración a un colectivo mayor ("el pueblo peronista") en términos similares a otros sectores activados que hacían uso de las nociones de jerarquía y autoridad asociadas a los sistemas de edad para legitimar sus propias posiciones. ${ }^{34}$ Cuando la "novela familiar peronista" llegaba a su final y, luego, con la imposición de la última dictadura en 1976, decenas de miles de esos "hijos del Cordobazo" o de otros "mayos" fueron asesinados y desaparecidos, y otros tantos exiliados. Entre algunos de ellos, afiliados a Montoneros, la conmemoración del décimo aniversario del Cordobazo coincidió con el lanzamiento de la llamada "contraofensiva", ocasión en la que se organizó una representación centrada en la heroicidad de los trabajadores cordobeses, y de la clase trabajadora argentina en 1979, una clase que -sostenía Roberto Cirilo Perdía- tenía en los peronistas montoneros a su "vanguardia" (como no lo habían tenido sus predecesores en Córdoba en 1969). ${ }^{35}$ Esa reivindicación poco puede haber sido escuchada o leída en la Argentina. En la década que siguió, sin embargo, nuevas construcciones generacionales fueron más consustanciales a los procesos de memoria social de la militancia.

\section{“Para mi generación..."}

Desde fines de la década de 1970 y, con mayor intensidad, en la década que siguió, la acción de denuncia y el reclamo de justicia por los crímenes cometidos durante la última dictadura militar (en particular, la desaparición forzada de personas) se organizó a partir del despliegue de una "clave humanitaria". Como lo ha mostrado Emilio Crenzel, viejos y nuevos organismos de derechos humanos, en sintonía con los requisitos y los lenguajes de circulación transnacional, construyeron sus denuncias a partir de la configuración de perfiles identitarios básicos de las personas desaparecidas (como edad o profesión). Esa "clave" pervivió en instancias cruciales luego de la recuperación de un orden político democrático, notablemente en la investigación de la Comisión Nacional sobre la Desaparición de Personas que dio como fruto el informe Nunca más (1984) y en

\footnotetext{
${ }^{33}$ Gordillo, Mónica, "Paso, paso, paso, se viene el Cordobazo: Mayo del '69 y los usos de la memoria”, Estafeta, núm. 32, 1999, pp. 41-45. Para descripciones sobre el 29 de mayo de 1973, ver "Cuba va del brazo, de nuestro Cordobazo", Estrella Roja, núm. 22, junio de 1973 y “Ayer lucha, hoy fiesta de liberación”, El descamisado, núm. 3, 5 de junio de 1973. ${ }^{34}$ Elaboré algunas de esas ideas en Manzano, La era de la juventud..., op. cit., cap. 6.

35 Roberto C. Perdía, "A diez años del Cordobazo, preparemos el Argentinazo", Evita Montonera, núm. 24, mayo de 1979, p. 11. Agradezco a Hernán Confino el haberme compartido la referencia.
} 
el contexto del Juicio a las Juntas Militares de 1985. La "clave humanitaria", que entre otros elementos suponía obliterar la filiación política y las actividades de militancia de las personas desaparecidas, fue constitutiva de lo que Crenzel denomina como el primer "régimen de memoria" sobre la dictadura y su pasado inmediato. ${ }^{36}$ Esta construcción corrió en paralelo a la intensa repolitización de segmentos importantes de la sociedad argentina. En los dos primeros tercios de la década de 1980, una nueva camada de activistas y militantes engrosó las ramas juveniles de la mayoría de los partidos. Los y las jóvenes buscaron, en buena medida, despegarse de sus pares de la década anterior, (auto) representándose como una juventud "madura y responsable", capaz de convivir en el disenso y baluarte de una nueva cultura democrática -tal lo expresado, por ejemplo, en el marco del Movimiento de las Juventudes Políticas (MOJUPO, creado en 1983 e integrado por jóvenes de la Unión Cívica Radical, del Partido Intransigente, del Partido Comunista, y de diversas ramas del peronismo, entre otros). Sin embargo, los jóvenes del MOJUPO -y de otras fuerzas políticas de izquierda que no lo integraban- no dejaban de lado una serie de programas y discursos centrados en el antiimperialismo y el latinoamericanismo, como así tampoco la idea misma de "revolución social". ${ }^{37}$ Como lo mostraban quizá de un modo extremo el llamado "viraje revolucionario" del Partido Comunista (consumado en 1986) y la fundación del Movimiento Todos por la Patria (también en 1986), los imaginarios de una revolución social no eran extemporáneos, mucho menos cuando esos y otros agrupamientos políticos tomaran a la Nicaragua sandinista como un faro. ${ }^{38}$ En el último tercio de la década de 1980, sin embargo, una serie de procesos convergieron para poner en cuestión, y eventualmente remitir al pasado, tanto las diversas ideas de "revolución" como la militancia política tal cual se entendía. Así, las transformaciones políticas globales (la Perestroika soviética en primera instancia), la emergencia de una corriente de desencanto con el proyecto encabezado por Raúl Alfonsín (desencanto que combinaba la frustración con la política económica y social, además de con las “leyes del perdón” de 1986 y 1987) y la serie de conmemoraciones sobre el '68, fueron las coordenadas para que viejos y nuevos activistas y militantes e intelectuales construyeran sentidos generacionales en los cuales los mecanismos de representación -e interpretación- del pasado "setentista" fueron centrales.

Las conmemoraciones por el vigésimo aniversario del "68 transnacional fueron el telón de fondo sobre el cual diversos actores políticos y culturales elaboraron ideas sobre la "pervivencia" de la revolución y, a partir de ello, configuraron también construcciones generacionales. Esas conversaciones se hacían visibles en el marco de una serie de emprendimientos periodísticos de carácter político-cultural significativos de la década de 1980, tales como el semanario El periodista de Buenos Aires, los mensuarios El porteño, Babel o Fin de Siglo y, en el último tercio de la década, los periódicos Página/ 12 y Nuevo Sur. Lanzada en 1987 y dirigida por Vicente Zito Lema, Fin de siglo ejemplifica el impulso inclusivo que, más allá de sus diferencias, atravesaba a aquellas publicaciones. De ese emprendimiento participaban viejos y nuevos periodistas, intelectuales y escritores, muchos de ellos con reconocida participación en organizaciones políticas de izquierda o peronistas en la década de 1970 -desde Rodolfo Mattarollo hasta Horacio Verbitsky- tanto como un conjunto de periodistas vinculados a la escena de tipo "contracultural" o al feminismo renovado -por ejemplo, Enrique Symns y María Moreno. En septiembre de 1987, Fin de siglo produjo un dossier especial, detonado por la reciente traducción de La revolución y nosotros, que la quisimos tanto, el libro en que se transcribían las entrevistas que Daniel Cohn-Bendit realizó, en 1985 y 1986, a figuras del '68 global, incluyendo a Jerry Rubin (el ex yippie norteamericano al que se retrataba, ahora, viviendo en un

\footnotetext{
${ }^{36}$ Crenzel, Emilio, La historia política del Nunca Más, Buenos Aires, Siglo XXI, 2008.

${ }^{37}$ Manzano, Valeria, "Juventud en transición: los significados políticos y culturales de la juventud en la Argentina de la década de 1980", en Branguier, Víctor y Elisa Fernández (eds.), Historia cultural, hoy: 13 entradas desde América Latina, Rosario, Prohistoria, 2018.

${ }^{38}$ Casola, Natalia, El PC Argentino y la última dictadura militar: militancia, estrategia política y represión estatal, Buenos Aires, Imago Mundi, 2015; Hilb, Claudia, "La Tablada: último acto de la guerrilla setentista", Lucha Armada en la Argentina, núm. 9, 2007, pp. 4-22, Fernández Hellmud, Paula, Nicaragua debe sobrevivir: la solidaridad de la militancia comunista argentina con la Revolución Sandinista (1979-1990), Buenos Aires, Imago Mundi, 2015.
} 
lujoso piso en Manhattan) y Joshcka Fischer (quien había pasado de activista estudiantil y sindical de la "extrema izquierda" a, por entonces, Ministro de Medioambiente socialdemócrata) junto a otras a ex activistas y militantes de origen estudiantil que continuaban encarcelados en Italia y Alemania. Antes que reproducir todas esas entrevistas, el dossier de Fin de siglo incluía la transcripción de una conversación entre Cohn-Bendit y Fernando Savater, en la cual éste le cuestionaba un sesgo interpretativo -el pasaje desde la "revolución" a la "integración", o bien a la "alienación" total- tanto como la no percepción de las diferencias posibles de los significados del "68 en diversas particularidades regionales o nacionales. Se trataba, diría Savater, de un '68 leído en clave de "espíritu de época" y asociado -en esto ambos coincidían- a una "generación con rostro joven”, cuya acción política en pos de una transformación social profunda se perdía en el recuerdo. ${ }^{39}$ Quizá para recuperar las particularidades regionales, y para poner en discusión también qué sentidos de izquierda y de revolución pervivían en América Latina, Fin de siglo solo transcribió la entrevista de Cohn-Bendit con Fernando Gabeira (un ex guerrillero brasilero que participó en el secuestro del embajador de Estados Unidos en 1969 y, tras años de prisión y exilio, abogaba por una "izquierda democrática" que además de preocuparse por la desigualdad social tomara en consideración temas como el machismo o el racismo) y produjo tres propias: con el líder del Frente Farabundo Martí de El Salvador, con un dirigente del Frente Patriótico Manuel Rodríguez de Chile, y con una dirigente de la Juventud Sandinista. ${ }^{40}$

Más fundamentalmente, tanto el dossier de Fin de siglo de 1987 (cuyo título general era "¿Qué queda de la revolución?") como el producido dos años después por Babel (titulado "La revolución ya no es lo que era" y publicado en el contexto de las conmemoraciones del bicentenario de la Revolución Francesa) convocaron a dos docenas de dirigentes y activistas políticos y sindicales tanto como de intelectuales y artistas argentinos a responder a esos interrogantes. En sus respuestas, una mayoría de aquellos que ya rondaban por los cincuenta años, transitó desde el singular al plural. "Para mi generación", planteaba el ex guerrillero peronista Envar el Kadri, "la revolución era una moneda corriente". Por su parte, el sociólogo Ernesto Villanueva -muy cercano a principios de la década de 1970 a los Montoneros- anotaba que "mi generación dio de sí lo mejor que ha podido", mientras concluía que "mi generación parece haber aprendido que la revolución es un sinsentido". Enrolado en otras vertientes del peronismo en la década de 1970, Julio Bárbaro sin embargo se sumaba a la misma línea argumentativa: "para mi generación, la revolución estaba atada al marxismo y al peronismo" sostenía, y ambos habían atravesado tantas transformaciones desde su "generación", que la idea misma de revolución social estaba perimida. La invocación generacional, sin embargo, fue compartida por intelectuales que no provenían de la tradición peronista. Así, Beatriz Sarlo reflexionaba sobre los sentidos de revolución en sus relaciones con la modernidad, indicando que "la revolución es, siempre, joven, como lo fuimos". Oscar Terán, por su parte, remitía al anclaje nacional del vocablo: "buena parte de mi generación", anotaba, "colmó esa palabra con el significado extraído ora en el socialismo libertario, ora en el marxismo especialmente de la III Internacional, y luego amasado en el ancho curso de la revolución cubana." ${ }^{41}$ Acicateados por procesos conmemorativos en los cuales se ponía en el centro de la escena la reflexión sobre los sentidos y la vigencia del término revolución, esos antiguos militantes e intelectuales enmarcaron sus reflexiones en un "nosotros" delineado en clave generacional.

\footnotetext{
39 "Polémica entre Cohn-Bendit y Savater", Fin de siglo, núm. 3, septiembre de 1987, pp. 30-32. Kristin Ross analizó el contexto político e intelectual de la producción de esas memorias, señalando que fueron uno de los hitos en la construcción de una interpretación culturalista, en clave generacional, del '68, ver May 68 and its Afterlives, Chicago, University of Chicago Press, 2005.

40 "No quiero ser un cosmonauta", "El poder y los revolucionarios", "No dejar al pueblo indefenso", "La dignidad, un hecho cotidiano", Fin de siglo, núm. 3, septiembre de 1987, pp. 33-36.

${ }^{41}$ Envar El Kadri, "Esa revolución tan amada" y Ernesto Villanueva, "La revolución es cosa de chicos", Fin de siglo, núm. 3, septiembre de 1987; Julio Bárbaro, "Un término fuera de juego", Beatriz Sarlo, "Esplendor y simplicidad" y Oscar Terán, "La Argentina, tierra de revoluciones", Babel, núm. 12, julio de 1989.
} 
Las construcciones generacionales del último tercio de la década de 1980 ponían en juego disputas en torno a las memorias sociales de los momentos intensos de activación política en los que -se entendía- se había fraguado un actor colectivo que ahora retomaba la voz pública para enmarcar aquel pasado. ${ }^{42}$ ¿Cuáles eran las referencias para las construcciones generacionales en la Argentina? ¿A qué procesos, momentos, dinámicas o acontecimientos evocaban? Mientras algunas de esas configuraciones remitían a "un espíritu de época" en el cual, ahora, convivían elementos políticos y culturales variados y globales -"desde Los Rolling Stones hasta la ofensiva del Tet, pasando por el secuestro de Aramburu", tal como ironizaba el por entonces muy joven periodista Marcelo Figueras $-{ }^{43}$, en otros casos militantes e intelectuales buscaban dilucidar especificidades y, al hacerlo, reconstruían o deconstruían sentidos e interpretaciones que se remontaban a comienzos de la década de 1970. Así, por ejemplo, también en el contexto de las conmemoraciones del vigésimo aniversario del '68, El porteño produjo su propio dossier. Uno de los convocados fue Enrique Dratman, un antiguo dirigente estudiantil comunista, quien sintéticamente indicó que, "en su momento, nadie recuperó al Mayo Francés" al cual él asociaba -como su partido, pero también buena parte de la prensa y los activistas habían hecho entonces- con "el rol desempeñado por la juventud y el estudiantado en los procesos revolucionarios". A su criterio (de 1988), ese "rol" fue corroborado "durante el Cordobazo, cuando el estudiantado fue la vanguardia de las luchas populares". Lejos de concebirlos como procesos o dinámicas similares, y más lejos aún de entrever la posibilidad de préstamos ideológicos o políticos, Dratman -y otros colaboradores del dossier- sí refirieron a la centralidad del movimiento estudiantil en ambos contextos, a los que entendieron como fundantes de "una generación". ${ }^{44}$ Para otros colaboradores, sin embargo, las revueltas del mayo argentino de 1969 pasaban inadvertidas. ${ }^{45}$ Así, por ejemplo, Horacio González aseguraba que "no tuvimos nuestro 1968 en 1968, lo tuvimos unos cinco años después", refiriendo entonces al momento breve de 1973 como "instancia liberadora". "Como había sucedido quince años atrás, para muchos de quienes se filiaban con peronismo que se auto-proclamaba revolucionario, sus referencias eran otros "mayos". A lo largo de la década de 1980, y al compás del proceso de reflexión y (auto) crítica sobre la lucha armada, quienes seguían filiándose con el peronismo especialmente el renovador, como González- fueron contribuyendo a singularizar al "mayo de 1973" (antes que al de 1970) como marca de referencia identitaria y anclaje para la construcción de un "nosotros" generacional. ${ }^{47}$

El mayo de 1969 -a diferencia del '68- tuvo su vigésimo aniversario en medio de la aguda crisis social y política marcada por la hiperinflación y los saqueos, además de la derrota electoral de Alfonsín y la decisión de anticipar la sucesión presidencial a Carlos Menem. Editorializando para La voz del interior, Julio César Moreno -él mismo un ex militante del movimiento estudiantil cordobés de fines de la década de 1960- escribía que "semejante aniversario nos encuentra envueltos en un clima de penumbra, miedo y malos presagios que ha hecho evocar, en la gente mayor, aquella jornada del 29 de mayo de 1969". En su lectura, la mayor diferencia era que "en una Córdoba y en

${ }^{42}$ Para México, ver Allier Montaño, Eugenia, "De la conjura a la lucha por la democracia: una historización de las memorias políticas del '68 mexicano”, en Allier Montaño, Eugenia y Emilio Crenzel, Las luchas por la memoria en América Latina: historia reciente y memoria política, México, Bonilla Artigas Editores, 2015, pp. 185-229.

${ }^{43}$ Marcelo Figueras, “Una flor radioactiva”, Nuevo Sur. 19 de mayo de 1989, Suplemento El Tajo, pp. 4-5.

${ }^{44}$ Enrique Dratman, "Nadie reivindicó al Mayo Francés”, El porteño, núm. 77, mayo de 1988, ver también Jorge Warley y Alberto Castro, "La universidad de la calle", Elporteño, núm. 77, mayo de 1988.

${ }^{45}$ Lo mismo sucedía en el dossier "Los textos de 1968", coordinado por Nicolás Casullo. Si bien Casullo reflexionaba sobre el "68 desde una perspectiva diferente, indicaba que "de aquel "68 nos separaría en la Argentina, esencialmente, el terror y la muerte”, ver “68, aquellas palabras de la tribu”, Babel, núm. 2, mayo de 1988, p. 23. El dossier incluye textos muy variados que harían a una "escritura d la revuelta", comenzando por Ho Chi Minh, Franz Fanon y Ernesto Guevara, y pasando por panfletos de estudiantes y trabajadores franceses hasta llegar a Perón y Cooke. Asimismo, el dossier incluía un pequeño recuadro de diez líneas, en el que se recupera un relato periodístico sobre el 29 de mayo de 1969 en Córdoba.

${ }^{46}$ Horacio González, "Marcooke”, El porteño, núm. 77, mayo de 1988.

${ }^{47}$ Para un estudio del peronismo renovador, ver Martina Garategaray, Unidos: la revista peronista de los ochenta, Bernal, Universidad Nacional de Quilmes, 2018. 
un país mucho más pobre que hace veinte años" persistían "los canales de expresión abiertos con la última restauración democrática". "Tanto en Córdoba como en Rosario, los actos de conmemoración fueron convocados por las fuerzas políticas que entonces conformaban Izquierda Unida -el Partido Comunista y el Movimiento al Socialismo- y reunieron concurrencias poco numerosas, de entre 2.000 y 4.000 personas que, además de recordar las jornadas de 1969 reclamaban por la liberación de los presos políticos y sociales de esas últimas semanas. ${ }^{49}$ A la vez, fue un diario de izquierda, Nuevo sur, uno de los pocos que produjo un dossier especial sobre mayo de 1969, en el cual primaban las reconstrucciones fácticas junto a pocos testimonios de dirigentes sindicales y estudiantiles. Como eje interpretativo, mientras tanto, el dossier reproducía el un fragmento del prólogo de El '69: huelga política de masas, de Beba y Beatriz Balvé (editado en esos meses por Contrapunto), en el cual las autoras reconocían que había sido en medio de un diálogo con un grupo de trabajadores rosarinos cuando habían decidido "producir un argumento totalizador" que colocara a mayo en una temporalidad más larga, la de 1969, en la cual -remarcabanpodía establecerse la "clara hegemonía obrera". ${ }^{50}$ Reseñando ese trabajo, Osvaldo Aguirre comentaba que la reconstrucción se recostaba en "una sola dimensión”, la de la prensa de época y los informes estatales, y que faltaba reconocer otras voces, las de "aquella generación", una tarea que intuía solo sería posible "a partir de los testimonios". ${ }^{11}$ Aunque el comentarista no tenía por qué saberlo, en la década que siguió "los testimonios" y, más generalmente, la literatura y el cine memorial, fueron una de las avenidas más importantes para las construcciones generacionales que siguieron tomando a los "mayos", sea separados o -con mayor frecuencia- juntos, como marco de referencia.

\section{Conclusiones}

Las "memorias del 69" de Carlos Altamirano fueron producidas en el marco del vigésimo quinto aniversario del Cordobazo. Ese fue un punto de inflexión fundamental en la construcción de memorias públicas respecto a aquel mayo. De hecho, tanto las memorias de Altamirano como otras intervenciones de intelectuales y antiguos militantes se discutieron en un encuentro organizado por la Universidad Nacional de Córdoba, y luego editadas en su revista institucional, Estudios. También en 1994 James Brennan publicaba, en inglés, uno de los primeros estudios de largo alcance sobre la historia de los trabajadores cordobeses y en 1996 la historiadora Mónica Gordillo haría lo propio al publicar -por el sello de la Universidad Nacional de Córdoba- una versión revisada de su tesis doctoral sobre la experiencia sindical en la década de 1960. Sólo por proseguir con ejemplos del ámbito universitario, en 1994 se creó en la Facultad de Filosofía y Letras de la Universidad de Buenos Aires la Cátedra Libre de Derechos Humanos -a cargo de Osvaldo Bayer- que devino una plataforma significativa para la producción de debates sobre, y la construcción de memorias en torno, la militancia previa al golpe de 1976. Con enfoques similares, la cátedra se extendió luego a la Facultad de Ciencias Sociales, donde se organizaron de periódicamente charlas y conversaciones con viejos militantes y activistas. ${ }^{52}$ Esas novedades del ámbito académico formaban parte de una trama mayor: un desplazamiento hacia nuevas formas de la memoria social sobre la dictadura $y$ su pasado inmediato en las cuales no solamente se "re-descubrían" los pasados políticos de las personas desaparecidas sino que, en el mismo movimiento, se revisitaban las formas y modos de hacer política en la Argentina de las décadas de 1960 y 1970. Como lo han mostrado otros investigadores, un hito clave en ese desplazamiento fue la conmemoración del vigésimo aniversario

\footnotetext{
48 Julio César Moreno, “Córdoba veinte años atrás”, La voz. del interior, 29 de mayo de 1989, p. 4.

49 "Hace veinte años, las barricadas", Nuevo sur, 22 de mayo de 1989, p. 6; "Pacífica marcha de la izquierda", La voz del interior, 30 de mayo de 1989, p. 7; "Recordación del Cordobazo", Nuevo sur, 30 de mayo de 1989, p. 4.

50 "El sentido del '69”, Nuevo sur, 28 de mayo de 1989, Suplemento Las palabras y las cosas, pp. 4-5.

51 Osvaldo Aguirre, “El ‘69”, Babel, núm. 12, julio de 1989.

${ }^{52}$ Ver Cristal, Yann, "El movimiento estudiantil de la Universidad de Buenos Aires en democracia (1983-2001", Tesis

Doctoral, Facultad de Filosofía y Letras, Universidad de Buenos Aires, 2019, pp. 174-5.
} 
del golpe de 1976, la emergencia del colectivo HIJOS y los procesos de interrogación e identificación con el pasado político de la "generación" anterior. ${ }^{53}$

A mediados de la década de 1990, así, la emergencia de esa cohorte de activistas y militantes encapsulada en -pero no limitada a- HIJOS, viene también a colaborar a suturar algunos de los debates, explícitos e implícitos, de las dinámicas de construcciones generacionales y a ponerle nombre a una entelequia: la "generación del setenta". Si, como intentó ilustrar este ensayo, los "mayos" sirvieron como marcos de referencia para que (al menos, parte de) los militantes de izquierda o peronistas produjeran construcciones generacionales en las que se ponían en disputa posiciones e interpretaciones de aquel presente (principios de la década de 1970) o aquel pasado (quienes hablaron a fines de la década de 1980), la irrupción de esta cohorte remitía a una generación anterior. Se trataba en primera instancia de los padres y madres desaparecidos, pero también de aquellos y aquellas que, habiendo sobrevivido, habían sido también parte de las dinámicas de intensa activación política de principios de la década de 1970. En tal sentido, jóvenes y adultos fueron decantando una construcción generacional en la que destacaba una novedad fundamental: había nacido la "generación del setenta". Tal construcción venía a indicar tres cuestiones. Por un lado, y de manera obvia, que las construcciones generacionales son parte de los procesos de memoria social y remiten al pasado y sus usos. ${ }^{54}$ Pueden haber $-\mathrm{y}$ de hecho, como intenté mostrar, hubieron- intentos "instantáneos" de producir representaciones en clave generacional, como por ejemplo "los hijos del Cordobazo". Contemporáneamente, los usos de esos nombres (esas identidades) tenían que ver con disputas que hacían a la coyuntura. Fue recién a fines de la década de 1980 cuando antiguos activistas y militantes hicieron uso del plural "mi generación" para enmarcar sus recuerdos y, desde ellos, sus interpretaciones del pasado (y de ese presente en el cual se revisaba el concepto de revolución). Por otro lado, que las construcciones generacionales implican instancias de debate, pero también de cristalización, muchas veces sintetizadas en un nombre. Como lo estudió Leerom Medovoi respecto a la "generación beat" en Estados Unidos, el nombramiento es consustancial a la representación y a las chances de generar interpelación. Así, las invocaciones a los "mayos", que funcionaron todavía en la década de 1980, suponían interpelaciones a parcialidades: su éxito solo podía ser relativo vis-a-vis a la más totalizante "generación del setenta". Por último, entonces, esa "generación del setenta" nace cuando una nueva cohorte (de "hijos", en el sentido general) emerge en la escena pública y política y actualiza procesos que son a la vez de identificación y de separación con la anterior. En ese contexto, en el cual dos cohortes se referenciaban en "los setenta", se opacaban las diferencias que persistían en las invocaciones a los "mayos". Aunque mucho más trabajo sea necesario, los sentidos y las interpretaciones que se proyectaron en la construcción de una "generación del setenta" fueron homogeneizantes y tendieron a focalizar en los mínimos comunes denominadores de toda una experiencia política y cultural diversa -mínimos comunes que podían ser una edad (la juventud de los protagonistas) o una característica de sus formas de activación política ("la voluntad").

En la construcción coral de la "generación del setenta" -que nació, lo recalco, a mediados de la década de 1990- resonaban pocos ecos y voces de las construcciones anteriores, las que aquí he propuesto leer como "los hijos de mayo". La historización de estas últimas, sin embargo, pueden colaborar a una mejor comprensión de las combinaciones posibles entre clave generacional y disputas políticas a principios de la década de 1970 y, más básicamente, de los modos en que a lo largo de la década de 1980 (especialmente en su último tercio), se procesaron en clave también generacional las transformaciones políticas y culturales que, en resumidas cuentas, se tildaban como

\footnotetext{
${ }^{53}$ Ver, entre otros, Bonaldi, Pablo, "Hijos de desaparecidos: entre la construcción de la política y la construcción de la memoria", en Jelin, Elizabeth y Diego Sempol (eds.), El pasado en el futuro: los movimientos juveniles, Buenos Aires, Siglo XXI, 2006, pp. 143-184; Cueto Rúa, Santiago, "Hijos de víctimas del terrorismo de estado: justicia, identidad y memoria en el movimiento de derechos humanos en la Argentina (1995-2008), Historia Crítica. núm. 40, 2010/11, pp. 122-145.

${ }^{54}$ Nora, Pierre, "Generations", en Nora, Pierre (ed.), Realms of Memory: The Constructions of the French Past, Nueva York, Columbia University Press, 1995, pp. 499-526.
} 
"el fin de la revolución". En ambos contextos, esas construcciones generacionales se instalaron como parte de un juego de escalas geográficas, y con ello también políticas y culturales. Mientras los militantes peronistas ligados a Montoneros en Córdoba enfatizaron su ligazón política y afectiva con el Cordobazo (diferenciándose con esto de sus compañeros de otras locaciones geográficas), una mayoría de los antiguos militantes e intelectuales de la década de 1980 elaboraron sus memorias de militancia en clave generacional en el marco de las conmemoraciones transnacionales que eclosionaron entre 1987 y 1989, cuando lo que se puso en disputa era la "vigencia de la revolución" y sus imaginarios. 